\title{
How Growth Ability of Multidrug-Resistant Escherichia coli Is Affected by Abiotic Stress Factors
}

\author{
Lucinda Janete Bessa1,2*, Vânia Filipa Dias ${ }^{3}$, Ângelo Mendes², Paula Martins-Costa ${ }^{4}$, \\ Helena Ramos ${ }^{4}$, Paulo Martins da Costa ${ }^{1,2}$ \\ ${ }^{1}$ CIIMAR - Interdisciplinary Center for Marine and Environmental Research, University of Porto, Porto, Portugal \\ ${ }^{2}$ ICBAS - Institute Abel Salazar for the Biomedical Sciences, University of Porto, Porto, Portugal \\ ${ }^{3}$ FCUP_Faculty of Sciences, University of Porto, Porto, Portugal \\ ${ }^{4}$ Serviço de Microbiologia, Centro Hospitalar do Porto, Hospital Geral de Santo António, Porto, Portugal \\ Email: ${ }^{*}$ Ibessa@ciimar.up.pt
}

Received 19 February 2014; revised 3 April 2014; accepted 22 April 2014

Copyright (C) 2014 by authors and Scientific Research Publishing Inc.

This work is licensed under the Creative Commons Attribution International License (CC BY).

http://creativecommons.org/licenses/by/4.0/

c) (7) Open Access

\section{Abstract}

The ability of multidrug-resistant Escherichia coli to adapt and grow in a wide range of different environmental conditions may be crucial to the global spread of antimicrobial resistance. The aim of this study was to evaluate the survival ability of 54 multidrug-resistant $E$. coli strains, isolated from three different biotopes (clinical setting, gull intestine, river water) when subjected to variations in $\mathrm{pH}$ (from 3 to 11 ) and salinity (from $0.5 \%$ to $6 \%$ of $\mathrm{NaCl}$ ) and to nutrient deprivation. The growth of each isolate as well as of a reference strain was assessed during $168 \mathrm{~h}$ in every varying condition. Slight variations in the growth ability under some abiotic stress factors were recorded among the isolates from the different biotopes. Multidrug-resistant isolates from gull feces were found to be the more tolerant to environmental abiotic changes, while isolates from river water were the less tolerant. In addition, it was notorious that the carriage of antimicrobial resistance has a clear fitness cost in comparison with the susceptible (reference) strain, highlighting the necessity of reducing the selective pressure exerted by antibiotics. This study underlines the ecological hardness of multidrug-resistant $E$. coli isolates with a consequent ability to reach and colonize new host and environments.

\section{Keywords}

Escherichia coli, Multidrug Resistance, Nutrient Deprivation, pH, Salinity

\footnotetext{
"Corresponding author.
} 


\section{Introduction}

The bacterial species Escherichia coli comprises a genetically diverse group of strains, with the majority being commensals of mammals, but others are pathogenic, causing either intestinal or extraintestinal disease [1]. Currently, the emergence of multidrug-resistant bacteria is becoming a worldwide concern and since E. coli acquires resistance easily and is commonly found in many different animal species, it is used for surveillance studies of antimicrobial resistance [2] [3].

Multidrug-resistant E. coli is widely distributed in the environment and it has been isolated from surface waters [4] [5], vegetables [6] [7] and even feces of gulls and other waterbirds [8]. The survival of these bacteria in the environment is related not only to the degree of bacterial contamination but also to its capability to endure (and even proliferate) in a wide range of abiotic stress factors, such as temperature, $\mathrm{pH}$, salt concentration and the amount of organic material. E. coli presents good growth at $37^{\circ} \mathrm{C}$ and $\mathrm{pH}$ between 6 and 8 , however, some reports indicate that it can tolerate a $\mathrm{pH}$ in the range 5 - 9, but adaptation to acid seems to be greater than to alkaline [9]. Enteric bacteria, when released into the sea, where the salt content is normally around 3.5\%, are subjected to an immediate increase in osmotic pressure [10], and to adapt to those osmotic changes they can take up or synthesize specific molecules (osmoregulators, such as potassium ions, glutamate, glycine-betaine) which act as osmotic balancing agents [11] [12]. E. coli is capable of utilizing several compounds (organic and inorganic) as carbon sources, depending on the nutrient availability; however, glucose is the preferred carbon source. Variations in those abiotic factors such as extremes of temperature, $\mathrm{pH}$ and salinity, nutrient deprivation and osmotic pressure can constitute environmental stresses, once they have an adverse effect on the physiological behavior of bacterial cells, leading to a reduction in the growth rate, or even inhibition of growth or cell death [13].

Thus, it is necessary to understand which factors among multidrug-resistant strains allow them to survive outside their hosts, enabling them to thrive in various interconnected ecological niches. Strains with higher ecological hardness have a larger probability to reach and colonize a new host and have a better capability to acquire new genetic determinants of both resistance and virulence. The network of gene exchange is shaped principally by ecology rather than geography or phylogeny, with most of the gene exchange occurring between isolates from ecologically similar, but geographically separated, environments [14].

The aim of this study was to evaluate the survival ability of 54 multidrug-resistant $E$. coli strains, isolated from three different biotopes (clinical setting, gull intestine, river water) when subjected to a variation in $\mathrm{pH}$ (from 3 to 11 ), salinity (from $0.5 \%$ to $6.0 \%$ of $\mathrm{NaCl}$ ) and nutrient deprivation (from a enrichment medium to only physiological solution, via intermediary dilutions of the medium).

\section{Materials and Methods}

\subsection{Bacterial Strains}

It was used a reference strain, E. coli ATCC 25922, and 54 E. coli strains isolated from three different biotopes: clinical isolates $(n=18)$ from patients with urinary tract infections admitted to an Hospital of Porto (HP); isolates $(n=18)$ from gull feces collected from Porto coastline $(G F)$ and isolates $(n=18)$ from river water samples collected from Ave River, in the north of Portugal (AR). All isolates were characterized and species identification was confirmed by biochemical tests, using an API 20E kit (bioMerieux, Craponne, France). A susceptibility testing assay was performed for all isolates using the disk diffusion method according to CLSI guidelines [15].

Strains were stored in glicerol at $-20^{\circ} \mathrm{C}$ until use and were maintained on Tryptic Soya Agar (TSA-Liofilchem, Roseto degli Abruzzi, Italy) slants. Fresh colonies were obtained by plating on Tryptone Bile X-Glucuronide agar (TBX_-Biokar Diagnostics, Alonne, France).

\subsection{Growth Medium and Ranges for Abiotic Factors}

Buffered Peptone Water (peptone, di-sodium phosphate and potassium dihydrogen phosphate)—BPW (Oxoid, Basingstoke, England) was the medium used to study the influence of the three abiotic factors on the growth of $E$. coli strains. The $\mathrm{pH}$ was adjusted by adding $\mathrm{NaOH}$ or $\mathrm{HCl}$ to BPW medium (range 3 to 11), the salinity was adjusted by adding $\mathrm{NaCl}$ to $\mathrm{BPW}$ medium (range $0.5 \%$ to $6.0 \%$ ) and nutrient deprivation was achieved by diluting the BPW medium in physiological solution (range from non diluted BPW to no BPW medium) (Table 1). 
Table 1. Range of values tested for each abiotic factor.

\begin{tabular}{ccc}
\hline $\mathbf{p H}$ & Salinity-NaCl (\%) & Nutrient deprivation-BPW dilution \\
\hline 3 & 0.5 & $\mathrm{Nd}$ \\
4 & 1.0 & $1: 1.125$ \\
5 & 1.5 & $1: 1.3$ \\
6 & 2.0 & $1: 1.5$ \\
7 & 2.5 & $1: 1.8$ \\
8 & 3.0 & $1: 2.25$ \\
9 & 3.5 & $1: 3$ \\
10 & 4.0 & $1: 4.5$ \\
11 & 4.5 & $1: 9$ \\
& 5.0 & No \\
& 5.5 & \\
& 6.0 & \\
\hline
\end{tabular}

Nd: no dilution (100\% BPW medium). No: no BPW medium (only physiological solution).

\subsection{Experimental Conditions for Survival Tests}

To test the influence of the three abiotic factors, 96-well plates were used. In the precedent day, the BPW medium adjusted to each value of the factor range to be tested was dispensed (180 $\mu \mathrm{l})$ into each well. The pre-prepared microplates were kept at $4^{\circ} \mathrm{C}$. In the next morning, inocula of each strain were prepared suspending overnight fresh colonies in physiological solution to achieve an $\mathrm{OD}_{600}$ between 0.015 and 0.020 . Then, $20 \mu \mathrm{l}$ of each inoculum were added to the respective wells of the microplate. After inoculation, microplates were incubated at $37^{\circ} \mathrm{C}$, with shaking (50 rpm) for $168 \mathrm{~h}$. At periodical intervals $(0,2,4,6,8,10,12,14,16,18,20,22,24,28,32$, $36,40,44,48,56,64,72,84,96,108,120,144$ e $168 \mathrm{~h}$ ), the absorbance at $570 \mathrm{~nm}$ was measured using a microplate photometer (Multiskan EX-Thermo Scientic, MA, USA).

\subsection{Statistical Analysis}

The statistical significance of difference among isolates from different biotopes was evaluated using one-way ANOVA and between each $E$. coli isolates group and $E$. coli reference strain was evaluated using Student's $t$ test. $P$ values $<0.05$ were considered statistically significant.

\section{Results and Discussion}

The influence of the variation of every abiotic factor in the growth of each one of the $54 \mathrm{E}$. coli isolates and the reference strain (E. coli ATCC 25922) was obtained during a period of $168 \mathrm{~h}$. For convenience in presenting the results, here it is shown the mean of $\mathrm{OD}_{570}$ values obtained from the isolates $(\mathrm{n}=18)$ coming from the same biotope (Figure 1). Moreover, the specific growth rate- $\mu\left(\mathrm{h}^{-1}\right)$ was calculated. Briefly, $\mathrm{OD}_{570}$ values were converted in natural logarithmic (ln $\left.\mathrm{OD}_{570}\right)$ and the slope of five adjacent points of the exponential phase was taken as the $\mu$, as follows:

$$
\mu=\frac{\Delta y}{\Delta x}
$$

In Equation (1): $\Delta y=\ln \left(\mathrm{OD}_{570}\right)_{10 \mathrm{~h}}-\ln \left(\mathrm{OD}_{570}\right)_{2 \mathrm{~h}}$ and $\Delta x=$ time $(10 \mathrm{~h})-$ time $(2 \mathrm{~h})$.

The specific growth rate values achieved are shown in Table 2.

In a very acidic condition ( $\mathrm{pH} 3$ ) no growth was observed for each one of the tested isolates. At $\mathrm{pH} 5$ they were able to grow but needed a longer period of adaptation to reach the maximal growth. In alkaline conditions (pH 9 and 11) they quickly adapted themselves but the maximal growth they have reached was much lower than 
E. coli GF
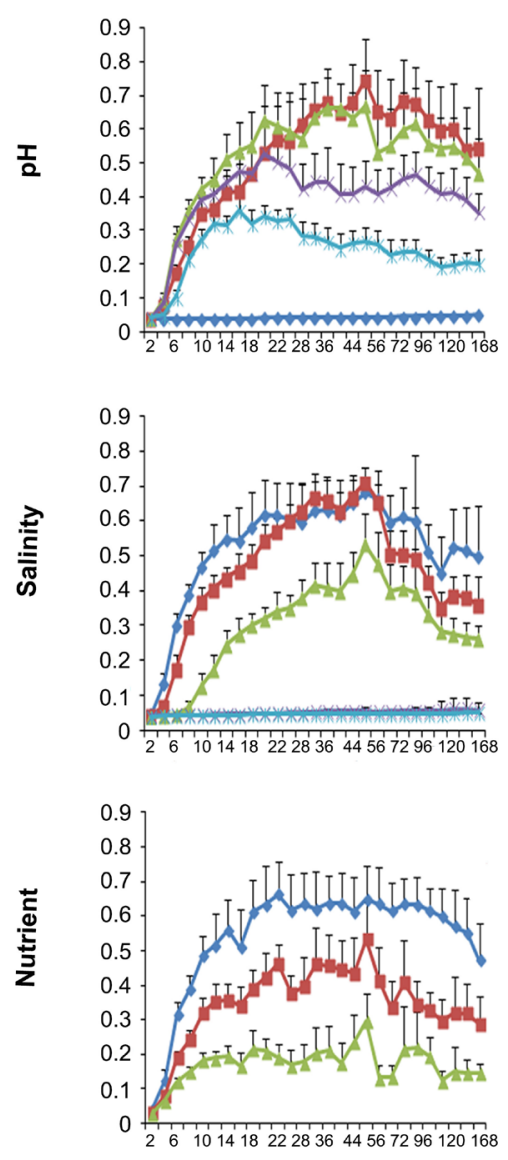

E. coli HP
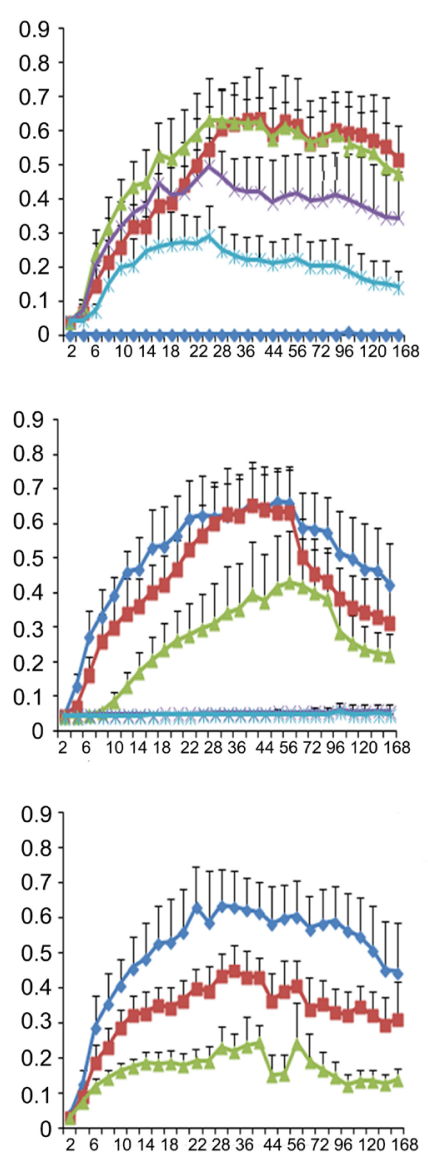

E. coli AR
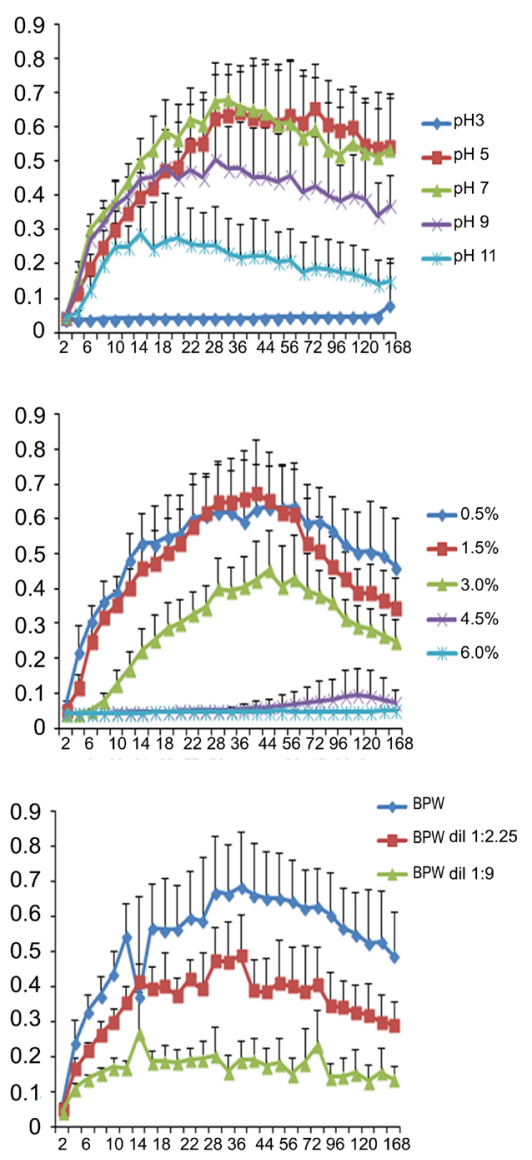

Figure 1. Growth assessment of multidrug-resistant $E$. coli from three biotopes (GF, HP, AR), through variation of $\mathrm{OD}_{570}$ during $168 \mathrm{~h}$, when exposed to different abiotic factors. The results shown are the mean of 18 isolates from each biotope. In the $Y$-axis are the $\mathrm{OD}_{570}$ values and in the $X$-axis is the time (h). Error bars represent standard deviations.

at $\mathrm{pH}$ 7, which was the preferred condition. Isolates from each biotope followed the same trend; presenting $\mu$ values very similar for each $\mathrm{pH}$ condition tested, however, E. coli GF were the isolates that could better tolerate changes in $\mathrm{pH}$.

Regarding the salinity, each group of isolates presented a similar behavior towards the different concentrations of $\mathrm{NaCl}$ assayed. A salinity of $0.5 \%$ was found to be the most favorable one. Salinity increase led to a decrease in growth. Salinity equal or lower than $4.5 \%$ seemed not to be propitious for E. coli proliferation. Isolates from AR were the most susceptible to salinity, while isolates GF were the ones that have better endured higher levels of salinity; with $\mu$ values at salinity $3.0 \%$ of $0.0223 \mathrm{~h}^{-1}$ and $0.1756 \mathrm{~h}^{-1}$, respectively. Wastewaters have been considered the most important sources of human-derived antibiotic resistance in coastline areas [8] [16], suggesting that colonization of gulls by ESBL-producing $E$. coli might occur more readily with strains displaying higher resistance to salinity. In addition, when they are excreted in gull feces they can persist in seawater (salinity of approximately 3.5\% [17]) and will have a higher probability of colonizing new hosts that are in close contact with seawater and beaches, like seabirds and humans.

It is well known that bacteria during starvation conditions have the ability to rapidly reduce the endogenous metabolic rate [18]. Therefore, nutrient deprivation had, as expected, a negative effect in the growth of multidrug-resistant $E$. coli. Similarly to what was reported for salinity, E. coli isolates GF were more tolerant to nutrient starvation than isolates from AR and HP. The lower ability of $E$. coli isolated from inpatients with urinary tract infections to adapt to nutrient deprivation was most likely a result of the fitness cost associated with the drawback of carrying important virulence genes that allow the colonization and adaptation to human urinary tract [19]. 
Table 2. Specific growth rate- $\mu\left(\mathrm{h}^{-1}\right)$ of $E$. coli isolates from each biotope and $E$. coli reference strain when exposed at different abiotic factors.

\begin{tabular}{|c|c|c|c|c|c|}
\hline \multicolumn{2}{|l|}{ Abitoc factor } & E. coli GF & E. coli HP & E. coli AR & E. coli ATCC 25922 \\
\hline \multirow{5}{*}{$\mathbf{p H}$} & 3 & 0.0041 & 0.0094 & 0.0051 & 0.0087 \\
\hline & 5 & $0.2839^{*}$ & $0.2469^{*}$ & $0.2321^{*}$ & 0.5250 \\
\hline & 7 & $0.3076^{*}$ & $0.2994^{*}$ & $0.2483^{*}$ & 0.5906 \\
\hline & 9 & $0.2977^{*}$ & $0.2721^{*}$ & $0.2525^{*}$ & 0.583 \\
\hline & 11 & $0.2357^{*}$ & $0.2227^{*}$ & $0.1834^{*}$ & 0.4238 \\
\hline \multirow{5}{*}{ Salinity } & $0.5 \%$ & $0.2908^{*}$ & $0.2647^{*}$ & $0.2052^{*}$ & 0.5759 \\
\hline & $1.5 \%$ & $0.2148^{*}$ & $0.1895^{*}$ & $0.1447^{*}$ & 0.5186 \\
\hline & $3.0 \%$ & $0.1756^{*}$ & $0.1648^{*}$ & $0.0223^{*}$ & 0.3758 \\
\hline & $4.5 \%$ & 0.0063 & 0.0065 & 0.0051 & 0.0080 \\
\hline & $6.0 \%$ & 0.0170 & 0.0092 & 0.0072 & 0.0081 \\
\hline \multirow{3}{*}{ Nutrient } & BPW & $0.3064^{*}$ & $0.2842^{*}$ & $0.2250^{*}$ & 0.6360 \\
\hline & BPW dil 1:2.25 & $0.2885^{*}$ & $0.2622^{*}$ & $0.2025^{*}$ & 0.6087 \\
\hline & BPW dil 1:9 & 0.2257 & 0.2001 & $0.1518^{*}$ & 0.3002 \\
\hline
\end{tabular}

Growth rate values are the mean of 18 isolates coming from each biotope (GF, HP, AR). The specific growth rate $\mu\left(\mathrm{h}^{-1}\right)$ was calculated as the slope of five adjacent points. *indicates a statistically significant.

In general, isolates GF were the most resistant to changes in those abiotic factors. The ability of these strains to grow in the aquatic environment (poor in nutrients and with high salinity), was essential to reach and colonize a new biotope like gull intestine. On the contrary, E. coli AR isolated from river water were found to be the less tolerant to changes in those abiotic factors. These multidrug-resistant strains were recovered after the first days of rainfall following the dry season that have dragged the fecal bacteria (present in the farmyard manure used to fertilize the cultivation areas in the surroundings of the river) to the river water. Thus, these strains may not have had the time to get adapted to the new environment, which may also explain their lower ability to tolerate variations in the abiotic factors studied. As stated by others [20] [21], the environment appears to be the main driving force for adaptation, however, it is also true that time has a crucial role to permit genomic and phenotypic innovations to happen. In addition, this group of strains (E. coli AR) was the one presenting the highest variability among themselves (high standard deviation) (Figure 1), which denotes the heterogeneity in their behavior, possibly due to the presence of strains with truly different backgrounds. In an interesting review, van Elsas et al. [22], have underpinned the $E$. coli ability to survive in various ecological niches and focused on the importance of studying E. coli behavior in its secondary habitat (especially soil and water resources) in order to better manage this microorganism from both environmental and public health perspectives.

A noteworthy result of our study was the fact that the reference strain was always able to reach a higher growth in comparison to the multidrug-resistant isolates (difference statistically significant for a $\mathrm{P}<0.05$ ) as shown in Table 2. Certainly, the genetic modifications involved in the acquisition of resistance to antibiotics can reduce the fitness of these pathogens [23] [24]. Therefore, the fitness cost associated with resistance can be a disadvantage in the absence of the selective pressure exerted by antibiotics. As wild type strains are genetically lighter (less burdened) than multidrug-resistant strains, they probably can bit the latter up (because they have faster rates of adaptation) in the absence of antibiotics [25]. This hypothesis may justify the reason why significant reductions in resistance require equally significant reductions in drug consumption [26] [27]. Knowing that the major selection pressure driving changes in the frequency of antibiotic resistance is the volume of drug use [26], it is demanding a decrease in the usage of antibiotics in human and veterinary medicine and as growth promoters [28]. Recently, many policies have been prompted to prevent unnecessary antibiotic use and to improve antimicrobial treatment protocols [29]. However, there are variability in the application of those prescribing restriction policies and, therefore, they are not always sufficient to eliminate resistance determinants, be- 
cause there are other factors than the fitness cost of resistance to take in account like the clonality of resistant isolates and co-selection by other antimicrobials [30]. To avoid co-selection, it is necessary to reduce the usage of all classes of antimicrobials [30].

Finally, more precise methodologies instead of absorbance measurement could have been used to evaluate the bacterial growth, such as metabolic activity assessment or flow cytometry analysis. However, those techniques would have hampered the use of such a wide number of isolates, which was our aim, as well as the accomplishment of so many measurements.

\section{Conclusion}

In conclusion, $E$. coli is a commensal of human intestine, but managed to reach and survive on many other environments such as gull intestine and river water and at the same time it acquired resistance to a great number of antimicrobial drugs. The evaluation of the ability of multi-resistant $E$. coli to tolerate drastic changes in abiotic factors is a crucial element to predict its ability to spread and to establish new colonizations.

\section{References}

[1] Chapman, T.A., Wu, X.-Y., Barchia, I., Bettelheim, K.A., Driesen, S., Trott, D., Wilson, M. and Chin, J.J.-C. (2006) Comparison of Virulence Gene Profiles of Escherichia coli Strains Isolated from Healthy and Diarrheic Swine. Applied and Environmental Microbiology, 72, 4782-4795. http://dx.doi.org/10.1128/AEM.02885-05

[2] Erb, A., Stürmer, T., Marre, R. and Brenner, H. (2007) Prevalence of Antibiotic Resistance in Escherichia coli: Overview of Geographical, Temporal, and Methodological Variations. European Journal of Clinical Microbiology and Infectious Diseases, 26, 83-90. http://dx.doi.org/10.1007/s10096-006-0248-2

[3] Tadesse, D.A., Zhao, S., Tong, E., Ayers, S., Singh, A., Bartholomew, M.J. and Mcdermott, P.F. (2012) Antimicrobial Drug Resistance in Escherichia coli from Humans and Food Animals, United States, 1950-2002. Emerging Infectious Diseases, 18, 741-749. http://dx.doi.org/10.3201/eid1805.111153

[4] Boon, P.I. and Cattanach, M. (1999) Antibiotic Resistance of Native and Faecal Bacteria Isolated from Rivers, Reservoirs and Sewage Treatment Facilities in Victoria, South-Eastern Australia. Letters in Applied Microbiology, 28, 164168. http://dx.doi.org/10.1046/j.1365-2672.1999.00517.x

[5] Ramírez Castillo, F.Y., Avelar González, F.J., Garneau, P., Márquez Díaz, F., Guerrero Barrera, A.L. and Harel, J. (2013) Presence of Multi-Drug Resistant Pathogenic Escherichia coli in the San Pedro River Located in the State of Aguascalientes, Mexico. Frontiers in Microbiololgy, 4, 147.

[6] Oliveira, M., Viñas, I., Usall, J., Anguera, M. and Abadias, M. (2012) Presence and Survival of Escherichia coli O157:H7 on Lettuce Leaves and in Soil Treated with Contaminated Compost and Irrigation Water. International Journal of Food Microbiology, 156, 133-140. http://dx.doi.org/10.1016/j.ijfoodmicro.2012.03.014

[7] Holvoet, K., Sampers, I., Callens, B., Dewulf, J. and Uyttendaele, M. (2013) Moderate Prevalence of Antimicrobial Resistance in Escherichia coli Isolates from Lettuce, Irrigation Water, and Soil. Applied and Environmental Microbiology, 79, 6677-6683. http://dx.doi.org/10.1128/AEM.01995-13

[8] Simões, R.R., Poirel, L., Da Costa, P.M. and Nordmann, P. (2010) Seagulls and Beaches as Reservoirs for MultidrugResistant Escherichia coli. Emerging Infectious Diseases, 16, 110-112. http://dx.doi.org/10.3201/eid1601.090896

[9] Rozen, Y. and Belkin, S. (2001) Survival of Enteric Bacteria in Seawater. FEMS Microbiology Reviews, 25, 513-529. http://dx.doi.org/10.1111/j.1574-6976.2001.tb00589.x

[10] Jones, G. (1971) The Fate of Freshwater Bacteria in the Sea. Developments in Industrial Microbiology, 12, $141-151$.

[11] Csonka, L.N. and Epstein, W. (1996) Osmoregulation. In: F. C. Neidhardt, Ed., Escherichia coli and Salmonella: Cellular and Molecular Biology. ASM Press, Washington DC, 1210-1223.

[12] Sinton, L.W. (2005) Biotic and Abiotic Effects. In: Oceans and Health: Pathogens in the Marine Environment. Belkin and Colwell, Springer, New York, 69-92. http://dx.doi.org/10.1007/0-387-23709-7_3

[13] McMahon, M.A.S., Xu, J., Moore, J.E., Blair, I.S. and McDowell, D.A. (2007) Environmental Stress and Antibiotic Resistance in Food-Related Pathogens. Applied and Environmental Microbiology, 73, 211-217. http://dx.doi.org/10.1128/AEM.00578-06

[14] Aminov, R.I. (2009) The Role of Antibiotics and Antibiotic Resistance in Nature. Environmental Microbiology, 11, 2970-2988. http://dx.doi.org/10.1111/j.1462-2920.2009.01972.x

[15] CLSI-Clinical and Laboratory Standards Institute (2012) Performance Standards for Antimicrobial Susceptibility Testing. Twenty-Second Informational Supplement. M100-S22. http://antimicrobianos.com.ar/ATB/wp-content/uploads/2012/11/M100S22E.pdf 
[16] Bonnedahl, J., Drobni, M., Gauthier-Clerc, M., Hernandez, J., Granholm, S., Kayser, Y., Melhus, A., Kahlmeter, G., Waldenström, J., Johansson, A. and Olsen, B. (2009) Dissemination of Escherichia coli with CTX-M Type ESBL between Humans and Yellow-Legged Gulls in the South of France. PLoS ONE, 4, Article ID: e5958. http://dx.doi.org/10.1371/journal.pone.0005958

[17] Munro, P.M., Gauthier, M.J., Breittmayer, V.A. and Bongiovanni, J. (1989) Influence of Osmoregulation Processes on Starvation Survival of Escherichia coli in Seawater. Applied and Environmental Microbiology, 55, 2017-2024.

[18] Colwell, R.R. (2000) Viable but Nonculturable Bacteria: A Survival Strategy. Journal of Infection and Chemotherapy, 6, 121-125. http://dx.doi.org/10.1007/PL00012151

[19] Qin, X., Hu, F., Wu, S., Ye, X., Zhu, D., Zhang, Y. and Wang, M. (2013) Comparison of Adhesin Genes and Antimicrobial Susceptibilities between Uropathogenic and Intestinal Commensal Escherichia coli Strains. PLoS ONE, 8, Article ID: e61169. http://dx.doi.org/10.1371/journal.pone.0061169

[20] Troussellier, M., Bonnefont, J., Dupray, E., Courtiesa, C., Derrienc, A., Gauthierd, M., Gourmelonc, M., Jouxe, F., Lebarone, P., Martinb, Y. and Pommepuy, M. (1998) Responses of Enteric Bacteria to Environmental Stresses in Seawater. Oceanologica Acta, 21, 965-981. http://dx.doi.org/10.1016/S0399-1784(99)80019-X

[21] Puentes-Téllez, P.E., Kovács, A.T., Kuipers, O.P. and van Elsas, J.D. (2013) Comparative Genomics and Transcriptomics Analysis of Experimentally Evolved Escherichia coli MC1000 in Complex Environments. Environmental Microbiology, 16, 856-870. http://dx.doi.org/10.1111/1462-2920.12239

[22] van Elsas, J.D., Semenov, A.V., Costa, R. and Trevors, J.T. (2011) Survival of Escherichia coli in the Environment: Fundamental and Public Health Aspects. ISME Journal, 5, 173-183. http://dx.doi.org/10.1038/ismej.2010.80

[23] Schrag, S.J., Perrot, V. and Levin, B.R. (1997) Adaptation to the Fitness Costs of Antibiotic Resistance in Escherichia coli. Proceedings of the Royal Society B: Biological Sciences, 264, 1287-1291. http://dx.doi.org/10.1098/rspb.1997.0178

[24] Perron, G.G., Gonzalez, A. and Buckling, A. (2007) Source-Sink Dynamics Shape the Evolution of Antibiotic Resistance and Its Pleiotropic Fitness Cost. Proceedings of the Royal Society B: Biological Sciences, 274, 2351-2356. http://dx.doi.org/10.1098/rspb.2007.0640

[25] Andersson, D.I. and Hughes, D. (2010) Antibiotic Resistance and Its Cost: Is It Possible to Reverse Resistance? Nature Reviews Microbiology, 8, 260-271.

[26] Austin, D.J., Kristinsson, K.G. and Anderson, R.M. (1999) The Relationship between the Volume of Antimicrobial Consumption in Human Communities and the Frequency of Resistance. Proceedings of the National Academy of Sciences of the United States of America, 96, 1152-1156. http://dx.doi.org/10.1073/pnas.96.3.1152

[27] Lipsitch, M. (2001) The Rise and Fall of Antimicrobial Resistance. Trends in Microbiology, 9, 438-444. http://dx.doi.org/10.1016/S0966-842X(01)02130-8

[28] Katsunuma, Y., Hanazumi, M., Fujisaki, H., Minato, H., Hashimoto, Y. and Yonemochi, C. (2007) Associations between the Use of Antimicrobial Agents for Growth Promotion and the Occurrence of Antimicrobial-Resistant Escherichia coli and Enterococci in the Feces of Livestock and Livestock Farmers in Japan. Journal of General and Applied Microbiology, 53, 273-279. http://dx.doi.org/10.2323/jgam.53.273

[29] CDC—Centers for Disease Control and Prevention (2013) Antibiotic Resistance Threats in the United States, 2013. http://www.cdc.gov/drugresistance/threat-report-2013/pdf/ar-threats-2013-508.pdf

[30] Enne, V.I. (2010) Reducing Antimicrobial Resistance in the Community by Restricting Prescribing: Can It Be Done? Journal of Antimicrobial Chemotherapy, 65, 179-182. http://dx.doi.org/10.1093/jac/dkp443 